\title{
Simple Sequence Repeat Markers Reveal Genetic Diversity Within and among Landrace Collections of Citron and Dessert Watermelon from South Africa
}

\author{
Jacob Mashilo ${ }^{1}$ \\ Crop Science Discipline, University of KwaZulu-Natal, Private Bag X01, Scottsville 3209, \\ Pietermaritzburg, South Africa; and Limpopo Department of Agriculture and Rural \\ Development-Towoomba Research Station, Private Bag X1615, Bela-Bela, 0480, South Africa \\ Hussein Shimelis \\ Crop Science Discipline, University of KwaZulu-Natal, Private Bag X01, Scottsville 3209, \\ Pietermaritzburg, South Africa; and African Centre for Crop Improvement (ACCI), University of \\ KwaZulu-Natal, Private Bag X01, Scottsville 3209, Pietermaritzburg, South Africa
}

\author{
Alfred Odindo \\ Crop Science Discipline, University of KwaZulu-Natal, Private Bag X01, Scottsville 3209, \\ Pietermaritzburg, South Africa
}

\begin{abstract}
Beyene Amelework
African Centre for Crop Improvement (ACCI), University of KwaZulu-Natal, Private Bag X01, Scottsville 3209, Pietermaritzburg, South Africa
\end{abstract}

\begin{abstract}
AdDITIONAL INDEX words. breeding, Citrullus lanatus, genetic relationship, population, microsatellites
Abstract. Genetic diversity analysis is fundamental for effective breeding and genetic conservation. The objective of this study was to determine the genetic diversity present among dessert watermelon (Citrullus lanatus var. lanatus) and citron watermelon ( $C$. lanatus var. citroides) landraces widely grown in South Africa and to select genetically diverse and complimentary genotypes for strategic breeding or conservation. Thirty-one dessert watermelon and 34 citron watermelon landraces were genotyped using 10 polymorphic simple sequence repeat markers. The number of alleles detected per marker ranged from 2 to 23 alleles, with a mean of 13.5 alleles. A total of 135 putative alleles were amplified from sampled watermelon populations. Number of effective alleles ranged from 1.99 to 10.88 alleles with a mean of 5.83 alleles. The mean observed and expected heterozygosity were 0.50 and 0.79 , respectively. The mean polymorphic information content was 0.79. Cluster and principal coordinate analyses grouped the two watermelon populations into two separate clusters. The two populations were genetically differentiated with low gene flow, suggesting the presence of high genetic differences between the two populations. Overall, the study established the existence of considerable genetic diversity among South African grown dessert and citron watermelon landraces. Unique dessert watermelon landraces such as SWM-39, SWM-24, SWM-01, SWM-40, SWM-18, SWM-36, and SWM-26; and citron watermelon genotypes including WWM-24, WWM-37, WWM-28, WWM-34, WWM-02, WWM-22, WWM-50, and WWM-36 were selected based on their high dissimilarity index. These could be useful for breeding and systematic conservation.
\end{abstract}

Watermelon is a viny creeping crop belonging to the Cucurbitaceae family. Chomicki and Renner (2014) using molecular phylogenetic analysis proposed six species under the genus Citrullus namely Citrullus lanatus, Citrullus mucosospermus, Citrullus colocynthis, Citrullus ecirrhosus, Citrullus rehmii, and Citrullus naudinianus. The authors further ascribed species Citrullus amarus to the citron watermelon. The Citrullus species are mainly found in the temperate regions of Africa, central Asia, and the Mediterranean Region (Levi et al., 2001a; Whitaker and Davis, 1962). The species C. lanatus composed of two botanical varieties: var. lanatus (dessert watermelon) and var. citroides (citron watermelon). The citron watermelon is neither sweet nor bitter and elsewhere known as "cow melon"

Received for publication 30 June 2016. Accepted for publication 9 Sept. 2016. The University of KwaZulu-Natal and the National Research Foundation of South Africa are acknowledged for financial support of this study.

${ }^{1}$ Corresponding author. E-mail: jacobmashilo@yahoo.com. or "tsamma" watermelon (Robinson and Decker-Walters, 1997). The southern Africa region is reported to be the center of diversity and probably center of origin of most of the species of Citrullus (Dane and Lang, 2004; Robinson and DeckerWalters, 1997; Rubatzky, 2001). However, Chomicki and Renner (2014) reported West Africa to be the origin of the egusi-type dessert watermelon.

Dessert watermelon is an important crop in drought-prone semiarid areas of Africa widely grown for its edible seeds and fruits and for animal feed (McGregor, 2012; Mujaju et al., 2010). Citron watermelon is orange-to-yellow fleshed serving for human food after cooking and for livestock feed (Nantoumé et al., 2013). Dessert watermelon is reported to have a relatively narrow genetic base (Levi et al., 2001b; Ocal et al., 2014; Solmaz and Sari, 2009), whereas citron watermelon possesses a high level of genetic variation (Dane and Liu, 2007; Levi et al., 2012). In southern Africa, watermelon is an underused and under-researched crop (McGregor, 2012). Some watermelon 
genotypes selected from South Africa were reportedly used in disease resistance breeding programs in the United States (Ma and Wehner, 2015; Mujaju et al., 2010; Tetteh et al., 2010; Thies et al., 2015). Furthermore, dessert and citron watermelon landrace collections of South Africa have been reported to be sources of resistance for many important diseases including root-knot nematodes (Meloidogyne incognita), bacterial fruit blotch (Pseudomonas avenae ssp. citrulli), gummy stem blight (Didymella bryoniae), and powdery mildew (Podosphaera xanthii) (Davis et al., 2007; Gusmini et al., 2005; Tetteh et al., 2010; Thies et al., 2010, 2015).

Genetic diversity analysis is fundamental for effective breeding and systematic genetic conservation. Various molecular markers have been used to assess genetic variability in watermelon such as randomly amplified polymorphic DNA (RAPD), amplified fragment length polymorphism (AFLP), sequence-related amplified polymorphism (SRAP), peroxidase gene-based polymorphism (POGP), high-frequency oligonucleotides (HFO), and simple sequence repeat (SSR) or microsatellite markers (Che et al., 2003; Levi et al., 2001b, 2012; Mujaju et al., 2010; Nantoumé et al., 2013; Ocal et al., 2014; Uluturk et al., 2011). Microsatellite markers are currently the marker of choice for genetic diversity analysis studies because of their high degree of polymorphism and random distribution across the genome (Gong et al., 2012; Ji et al., 2012; Varshney et al., 2005). These markers have been successfully used to determine the level of genetic diversity in watermelon (Mujaju et al., 2011; Nantoumé et al., 2013; Nimmakayala et al., 2009).

A genetic diversity study using SSR markers differentiated landraces of dessert watermelon from citron watermelon in Zimbabwe (Mujaju et al., 2011). A study by Minsart et al. (2011) using SSR markers revealed genetic differences among accessions of egusi watermelon. Several other studies using SSR markers indicated the existence of considerable levels of genetic diversity within dessert and citron watermelon cultivars (Mujaju et al., 2010; Munisse et al., 2013). Using SSR markers, Jarret et al. (1997) reported genetic differentiation between dessert watermelon and citron watermelon cultivars acquired from Chad and Nigeria. Levi et al. $(2001 \mathrm{~b}, 2012)$ assessed the diversity of PIs of watermelon from southern Africa using SSR markers and reported distinct genetic variation. There is increased interest among watermelon breeders in introducing new germplasm from different geographical regions for genetic improvement of the crop
(Yang et al., 2016; Zhang et al., 2012). However, information on the magnitude and effective utilization of genetic variation in watermelon has not been well documented (Hashizume et al., 2003; Weng et al., 2016). Incorporation of genes from elite introduced cultivars or citron germplasm is important in watermelon breeding programs (Hwang et al., 2011).

In South Africa, smallholder farmers grow unimproved landraces of dessert and citron watermelon that exhibit considerable morphological diversity including variations in fruit shape, exocarp coloring patterns, and seed morphology (Hashizume et al., 2003). This variation could have been due to many years of domestication and selection. Watermelon landraces grown and maintained by smallholder farmers in the country could be useful genetic resources to improve yield and yield-related traits, quality, and for biotic and abiotic stress resistance, breeding. Local watermelon breeding programs are largely dependent on PIs from the U.S. Department of Agriculture germplasm collections. The local watermelon breeding gene pool contained a limited number of South African cultivars (Che et al., 2003; Levi et al., 2001a, 2012; Nimmakayala et al.,

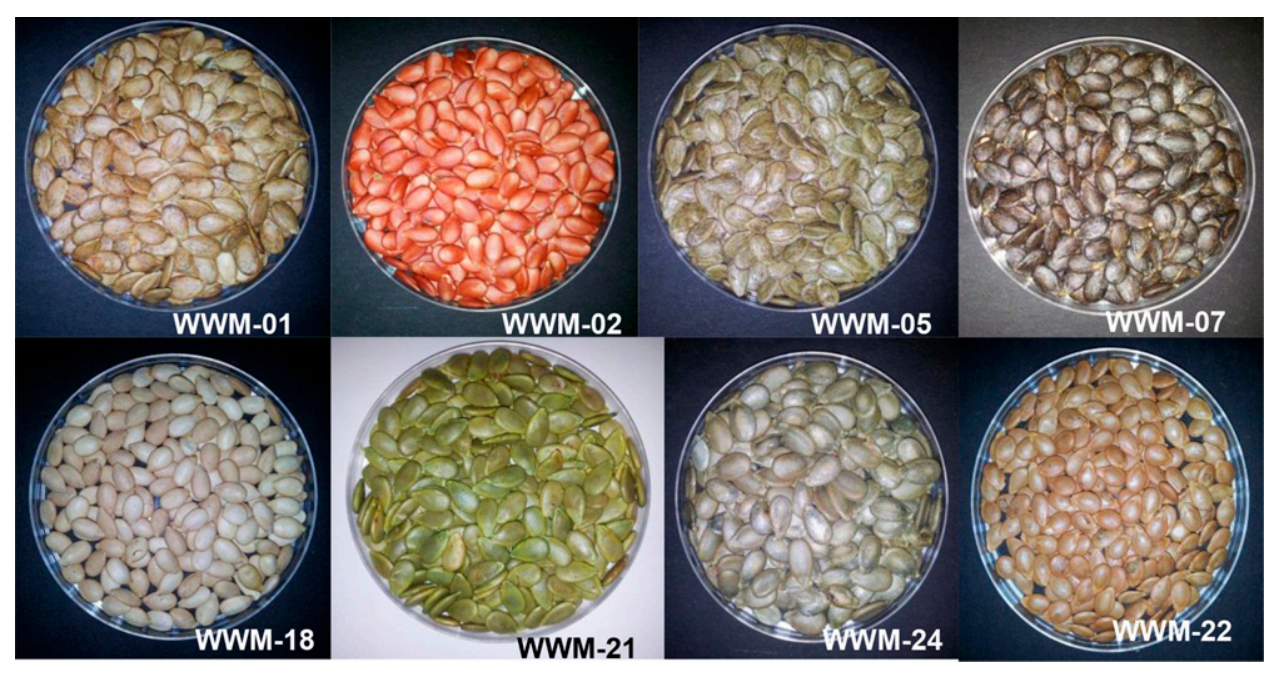

Fig. 1. Differences in seed morphotypes of selected citron watermelon landrace collections. See Table 1 for information related to the location and district of collection in the Limpopo Province, South Africa.
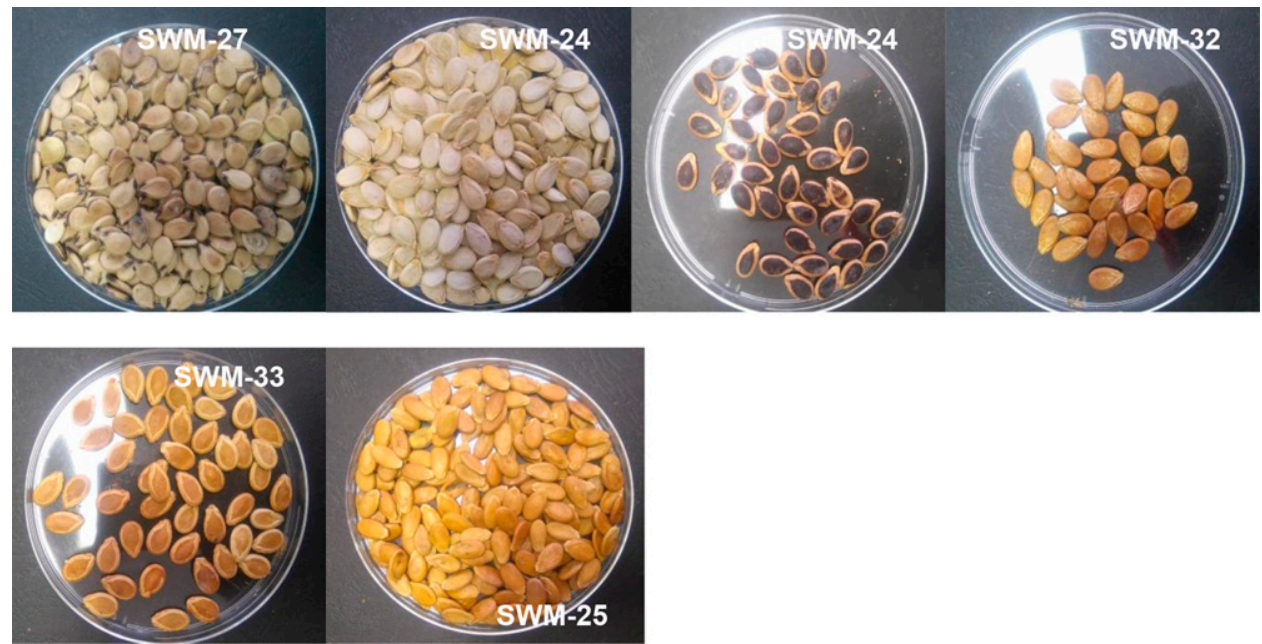

Fig. 2. Differences in seed morphotypes of selected dessert watermelon collections. See Table 1 for information related to the location and district of collection in the Limpopo Province, South Africa. 
2009; Solmaz et al., 2010; Zhang et al., 2016). Watermelon breeding programs in the country establish the genetic relationships of germplasm through phenotypic characterization. As such there have been no prior studies on genetic clustering of South African watermelon collections using molecular data. Therefore, it is important to develop systematic genetic groupings using diverse genetic pool of watermelon well adapted to local growing conditions. This will assist in developing cultivars in a reduced timeline in South Africa or other breeding programs. The efficiency of genetic classification of genotype-based genetic distance estimates depends on the availability of polymorphic SSR markers. Therefore, the objective of this study was to determine the genetic diversity present among dessert and citron watermelon landraces widely grown in South Africa and to select genetically diverse and complimentary genotypes for breeding and strategic conservation.

\section{Materials and Methods}

\section{Plant materials}

Thirty-one dessert and 34 citron watermelon landraces collected from Capricorn, Waterberg, and Sekhukhune districts of the Limpopo Province of South Africa were used in the study. Seed or fruit samples of dessert and citron watermelon were provided by farmers (Figs. 1-4). Dessert watermelon are mainly grown for their sweet red flesh (Fig. 3) for fresh consumption. Citron watermelon have a yellow or orange flesh color (Fig. 4). It is eaten cooked and referred to as "kgodu" in Sepedi, one of the main languages of South Africa. Table 1 summarises information related to the collection sites of landraces.

\section{DNA extraction, purification, and quantification}

Seed of diverse dessert and citron watermelon landraces were planted in 2-L polyethylene pots at the Controlled Research Facility, University of KwaZulu-Natal, Pietermaritzburg, South Africa (lat. $29^{\circ} 37^{\prime} 51.75^{\prime \prime} \mathrm{S}$, long. $30^{\circ} 23^{\prime} 59.10^{\prime \prime} \mathrm{E}$ ). Young fresh leaves were harvested from 40 plants per landrace 6 weeks after planting. The leaf samples were sent to Proteios laboratory (Incotec, Mkondeni, Pietermaritzburg, South Africa) for SSR analysis. The DNA was extracted following the $\mathrm{CTAB}$ (mixed alkyltrimethyl-ammonium bromide protocol) as described by CIMMYT (2005). The concentration of the extracted DNA was determined using $0.7 \%$ Tris-borate-EDTA (TBE) agarose gel. A working concentration of $10 \mathrm{ng} \cdot \mu \mathrm{L}^{-1}$ was standardized for all extracted DNA. The samples were bulked and used in SSR amplification.

\section{Polymerase chain reaction and SSR analyses}

All samples were used in bulked amplification, using DNA extracted from the leaf material. SSR sequences were amplified through polymerase chain reaction (PCR) using SSR primers specific for watermelon. Ten SSR markers were used for the analysis (Table 2). The markers were selected based on their high polymorphic information content and that they were developed for watermelon (Joobeur et al., 2006; Zhang et al., 2012). High polymorphic information content values suggest markers may have high discriminatory power to distinguish differences between the genotypes. PCR were performed for all the 10 primers. PCR products were fluorescently labeled and

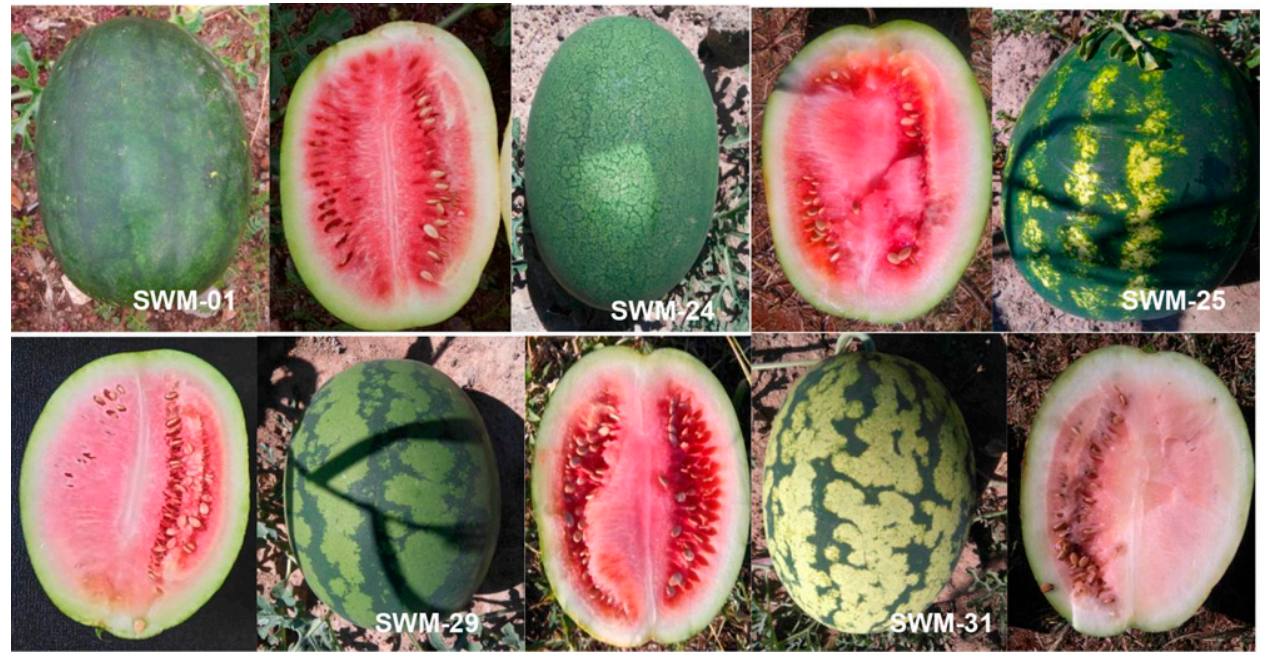

Fig. 3. Variation in fruit color and stripe patterns of selected dessert watermelon collections from South Africa used in the study. Dessert watermelon are mainly grown for their sweet red flesh for fresh consumption. See Table 1 for information related to the location and district of collection in the Limpopo Province, South Africa.
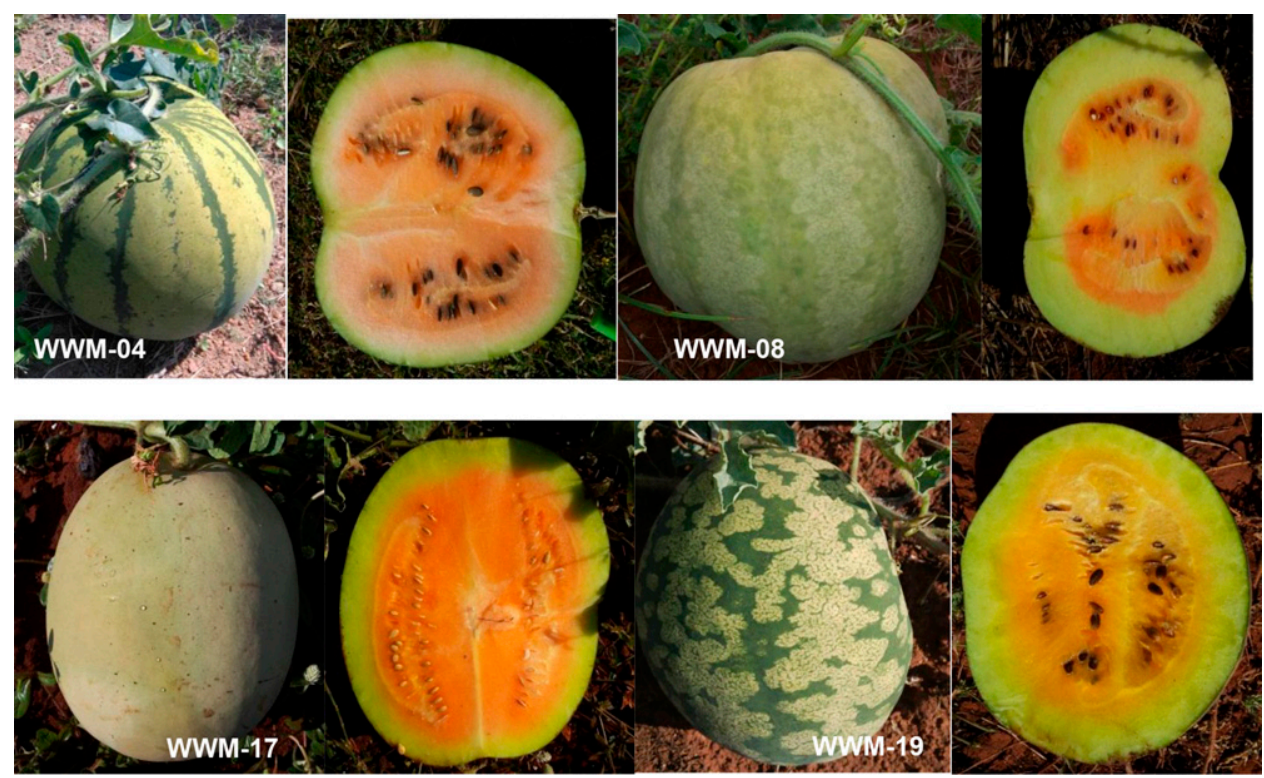

Fig. 4. Variation in fruit color and stripe patterns of selected citron watermelon collections from South Africa used in the study. The citron watermelon has a yellow or orange flesh color which is eaten cooked. See Table 1 for information related to the location and district of collection in the Limpopo Province, South Africa. 
Table 1. List of dessert watermelon (SWM) and citron watermelon (WWM) landrace collections used in the study. Locations and districts of collection are in the Limpopo Province of South Africa.

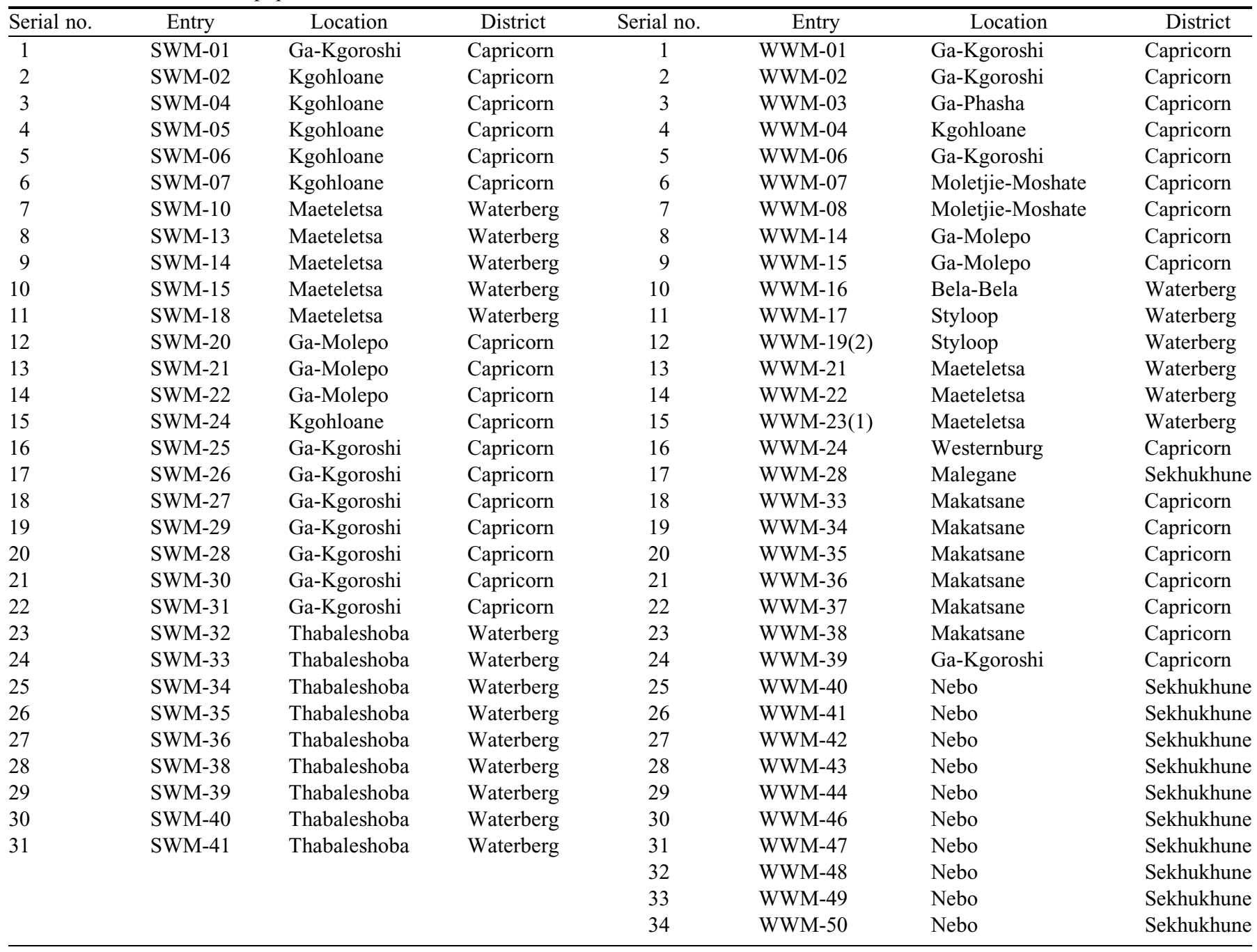

Table 2. Description of the SSR primers used for dessert watermelon and citron watermelon genetic diversity analyses.

\begin{tabular}{|c|c|c|c|}
\hline SSR primer & Forward primer $\left(5^{\prime} \rightarrow 3^{\prime}\right)$ & Reverse primer $\left(3^{\prime} \rightarrow 5^{\prime}\right)$ & $\mathrm{PIC}^{\mathrm{z}}$ \\
\hline$\overline{\mathrm{MCPI}-03}$ & GCATAAACCACCTGTGAGTGG & ATGGCTTTGCGTTTCATTTC & 0.80 \\
\hline MCPI-12 & GGAGTAGTGGTGGAGACATGG & TCСТTTCTCTTTCGCAAACTTC & 0.80 \\
\hline MCPI-37 & ААТСТTССССАTGCCAAAAC & GACTTCCAАACССТСССТTC & 0.87 \\
\hline MCPI-13 & TTCCTGTTTCATGATTCTCCAC & TCAGAATGGAGCCATTAACTTG & 0.88 \\
\hline MCPI-14 & TCAAATCCAACCAAATATTGC & GAGAAGGAAACATCACCAACG & 0.97 \\
\hline BVWS01734 & AAAATTACATCTTAAATGCGCC & GGAACATTGACTTCAATCAGCA & 0.74 \\
\hline BVWS00209 & TGCTTCAAAATCTATTCACAATTTGC & TTCTTGGTTTCGGGTTTCTTTACA & 0.79 \\
\hline BVWS00228 & GGAAGAGTGAGGTGATAAATCAATATGT & AATTGGCCCAAATATCCATATGAC & 0.74 \\
\hline
\end{tabular}

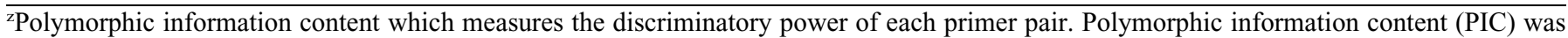
calculated using the formula: PIC $=1-\sum P_{i j}{ }^{2}$, where $P_{i j}$ is the frequency of $j$ th allele of the $i$ th locus (Nagy et al., 2012). SSR markers were selected based on their high PIC values and that they were developed for specifically for watermelon (Joobeur et al., 2006; Zhang et al., 2012).

separated by capillary electrophoresis on an automatic sequencer (ABI 3130; Applied Biosystems, Johannesburg, South Africa).

\section{Data analysis}

GeNeTIC DIVERSITY ANALYSIS. Two approaches were adopted to investigate the genetic structure and diversity among the watermelon genotypes. In the first approach, polymorphisms were treated as binary data (presence or absence). To determine the genetic structure within and among landraces, a second approach based on the codominant nature of the markers was adopted using GenAlex version 6.5 (Peakall and Smouse, 2012). 
Analysis of Genetic Parameters. Genetic diversity parameters, such as number of alleles per locus $\left(N_{\mathrm{a}}\right)$, number of effective alleles per locus $\left(N_{\mathrm{e}}\right)$, observed $\left(H_{\mathrm{o}}\right)$ and expected $\left(H_{\mathrm{e}}\right)$ heterozygosity, and Shannon's Information Index $(I)$ were calculated using GenAlex version 6.5 (Peakall and Smouse, 2012) according to the protocol described by Nei and Li (1979). The number of polymorphic loci was estimated for each predetermined group, based on the districts of collection. Further, an indirect estimate of the level of gene flow $\left(N_{\mathrm{m}}\right)$ between the two populations and districts of collection was calculated using the formula: $N_{\mathrm{m}}=0.25\left(1-F_{\mathrm{ST}} / F_{\mathrm{ST}}\right)$ using GenAlex. The Fstatistics such as genetic differentiation $\left(F_{\mathrm{ST}}\right)$, fixation index or inbreeding coefficient $\left(F_{\text {IS }}\right)$, and overall fixation index $\left(F_{\text {IT }}\right)$ were calculated according to Wright's original derivation (Wright 1951). Polymorphic information content (PIC) was calculated using the formula: $\mathrm{PIC}=1-\sum P_{\mathrm{ij}}{ }^{2}$, where $P_{\mathrm{ij}}$ is the frequency of $j$ th allele of the $i$ th locus (Nagy et al., 2012). Nei's unbiased genetic distance (GD) was also estimated to determine the degree of population differentiation among the studied materials. Nei's unbiased GD and genetic identity (GI) were estimated according to Nei (1978) using GenAlex.

Genetic Distance AND Cluster anAlysis. The binary data were used to obtain a dissimilarity matrix using the Jaccard index. The matrix was used to run a cluster analysis based on neighbor-joining employing the software DARwin 5.0 (Perrier and Jacquemoud-Collet, 2006). A dendrogram was generated on the dissimilarity matrix. Bootstrap analysis was performed for

Table 3. Genetic parameters generated by 10 SSR markers among dessert watermelon and citron watermelon landraces collected from three districts in the Limpopo Province, South Africa.

\begin{tabular}{lcrcccc}
\hline & \multicolumn{7}{c}{ Genetic parameter $^{z}$} \\
\cline { 2 - 7 } SSR primer & \multicolumn{1}{c}{$N_{a}$} & $N_{e}$ & $H_{o}$ & $H_{e}$ & \multicolumn{1}{c}{$F$} & $P I C$ \\
\hline MCPI-03 & 2 & 1.99 & 0.05 & 0.50 & 0.91 & 0.50 \\
MCPI-12 & 10 & 5.59 & 0.78 & 0.83 & 0.05 & 0.82 \\
MCPI-37 & 18 & 7.81 & 0.94 & 0.88 & -0.07 & 0.87 \\
MCPI-21 & 8 & 4.50 & 0.26 & 0.78 & 0.66 & 0.78 \\
MCPI-13 & 12 & 7.13 & 0.29 & 0.87 & 0.67 & 0.86 \\
MCPI-14 & 13 & 3.93 & 0.51 & 0.75 & 0.32 & 0.75 \\
BVWS01734 & 17 & 8.20 & 0.87 & 0.89 & 0.01 & 0.88 \\
BVWS00433 & 23 & 10.88 & 0.69 & 0.92 & 0.24 & 0.91 \\
BVWS00209 & 18 & 5.09 & 0.33 & 0.81 & 0.59 & 0.80 \\
BVWS00228 & 14 & 3.19 & 0.30 & 0.69 & 0.57 & 0.69 \\
Mean & 13.50 & 5.83 & 0.50 & 0.79 & 0.39 & 0.79 \\
SE & 1.89 & 0.85 & 0.10 & 0.04 & 0.11 & 0.04
\end{tabular}

${ }^{\mathrm{z}}$ Number of alleles per locus $\left(N_{\mathrm{a}}\right)$, number of effective alleles per locus $\left(N_{\mathrm{e}}\right)$, observed $\left(H_{\mathrm{o}}\right)$ and expected heterozygosity $\left(H_{\mathrm{e}}\right)$, fixation index $(F)$, polymorphic information content (PIC). node construction using 10,000 bootstrap values to estimate the reliability of the clustering pattern. Principal coordinates analysis was performed on the genetic distance matrix using PAST (Hammer et al., 2001). The first two principal components were plotted for visual examination of the clustering pattern of the landraces to complement clustering or grouping patterns revealed by the dendrogram.

ANALysis OF MOLECUlar VARIANCE. The partitioning of total genetic variation using analysis of molecular variance (AMOVA) was performed to estimate population genetic structure and differentiation among and within dessert and citron watermelon landrace collections. AMOVA uses the estimated F-statistics such as $F_{\mathrm{ST}}, F_{\mathrm{IS}}$, and $F_{\text {IT }}$ to compare the genetic structure among and within populations. For easy management and utilization, the total molecular variance was dissected into within and among population variations. The AMOVA procedure was done using a molecular analysis of variance procedure using GenAlex 6.5 according to Nei (1978).

\section{Results}

Polymorphism AND ALlelic DIVERSITY OF SSR MARKERS. Estimates of genetic parameters are presented in Table 3. The 10 SSR markers generated a total of 135 putative alleles for the sampled watermelon populations. Number of alleles ranged from 2 for the marker MCPI-03 to 23 alleles for marker BVWS00433, with a mean of 13.5 alleles per locus. Number of effective alleles ranged from 1.99 to 10.88 alleles with a mean of 5.83 alleles. $H_{\mathrm{o}}$ values ranged from 0.05 to 0.94 , with a mean of 0.50 , in other words, half of the loci were heterozygous and the remaining half of the loci reached acceptable level of homozygosity. Marker MCPI-03 had the lowest $H_{\mathrm{o}}$ value $(0.05)$, whereas marker MCPI-37 had the highest $H_{\mathrm{o}}$ value $(0.94) . H_{\mathrm{e}}$, as a measure of allelic diversity at a locus, ranged from 0.5 (MCPI-03) to 0.92 (BVWS00433) with a mean of 0.79 ; suggesting that $79 \%$ of the genetic individuals are expected to be heterozygous at a given locus under random mating conditions. Fixation index exhibited contrasting values ranging from -0.07 and 0.91 with a mean of 0.39 . F represents the average deviation of the population's genotypic proportions from Hardy-Weinberg equilibrium for a locus. A negative $\mathrm{F}$ value represents an excess of heterozygotes. For example, for locus MCPI-37, $88 \%$ of the watermelon population are expected to be heterozygous at the specific locus under random mating conditions; however, 94\% of the genotypes at this locus were heterozygotes. The PIC for the 10 SSR markers ranged from 0.5 to 0.91 , with a mean of 0.79 . Over $80 \%$ of the SSR-loci had PIC value of $>0.75$, indicating an adequate discriminatory power of individual SSR loci used in

Table 4. Genetic parameter estimates of dessert watermelon (SWM) and citron watermelon (WWM) populations collected from three districts in the Limpopo Province, South Africa. ${ }^{\mathrm{z}}$

\begin{tabular}{lcccccccccc}
\hline & \multicolumn{10}{c}{ Genetic parameter $^{2}$} \\
\cline { 2 - 10 } Population & $\mathrm{n}$ & $N_{\mathrm{a}}$ & $N_{\mathrm{e}}$ & $I$ & $H_{\mathrm{o}}$ & $H_{\mathrm{e}}$ & $F$ & PIC & PPL \\
SWM & 31 & 9.40 & 4.61 & 1.55 & 0.53 & 0.66 & 0.18 & 0.65 & 100.00 & 49.000 \\
WWM & 34 & 8.60 & 3.54 & 1.36 & 0.48 & 0.60 & 0.18 & 0.59 & 100.00 & 41.000 \\
Mean & 31.95 & 9.00 & 4.08 & 1.46 & 0.50 & 0.63 & 0.18 & 0.62 & 100.00 \\
SE & 0.44 & 1.03 & 0.55 & 0.16 & 0.07 & 0.06 & 0.07 & 0.03 & 0.00 & - \\
\hline
\end{tabular}

${ }^{2}$ Number of observations $(\mathrm{n})$, number of alleles per locus $\left(N_{\mathrm{a}}\right)$, number of effective alleles per locus $\left(N_{\mathrm{e}}\right)$, Shannon's information index $(I)$, observed $\left(H_{\mathrm{o}}\right)$ and expected $\left(H_{\mathrm{e}}\right)$ heterozygosity, fixation index $(F)$, polymorphic information content (PIC), percentage polymorphic loci (PPL), number of private alleles (NPA). 
the study. This suggested the potential of these loci for genetic diversity analysis in watermelon.

GENETIC VARIABILITY WITHIN AND AMONG WATERMELON POPULATIONS. Interpopulation analysis of genetic diversity indicated variation among the populations for all the genetic parameters (Table 4). Significant differences were detected in the mean number of observed and effective alleles for dessert watermelon population at 9.4 and 4.6 alleles, and citron watermelon population at 8.6 and 3.5 alleles, respectively. Shannon's information index was higher in dessert watermelon than citron watermelon population with mean values of 1.55 and 1.36, respectively. Both mean values of observed and expected heterozygosity for dessert watermelon were higher than those of citron watermelon. $H_{\mathrm{e}}$ is the probability that, at a single locus, any two alleles, chosen at random from the subpopulation, are different to each other. The average $H_{\mathrm{e}}$ overall loci value was significantly high for accessions from dessert watermelon population, indicating presence of higher genetic diversity in this specific population. No differences were observed with regard to fixation between the two populations. Of the $10 \mathrm{SSR}$ markers studied, $62 \%$ were polymorphic, on average at the population level. Private alleles, number of alleles found in a single subpopulation, was higher for dessert watermelon population. Percentage of polymorphic loci's or variable loci among the populations showed no significant variation between the two populations. The collections from both dessert and citron watermelon were $100 \%$ polymorphic across all loci. Overall, dessert watermelon showed the highest values of all genetic parameters than citron watermelon population, except for fixation index and percentage polymorphic loci (Table 4). These suggest that dessert watermelon possesses higher genetic diversity than citron watermelon.

Pairwise estimates of gene flow, genetic differentiation, genetic distance, and genetic identity among dessert and citron watermelon population are summarized in Table 5. $F_{\mathrm{ST}}$ among

Table 5. Pairwise estimates of gene flow (above diagonal, within the brackets), genetic differentiation (above diagonal without brackets); genetic distance (lower diagonal without brackets) and genetic identity (lower diagonal within the brackets) between dessert watermelon (SWM) and citron watermelon (WWM) populations collected from three districts of the Limpopo Province, South Africa.

\begin{tabular}{lcc}
\hline Population & SWM & WWM \\
\hline SWM & & $0.244(0.775)$ \\
WWM & $2.087(0.124)$ & \\
\hline
\end{tabular}

the watermelon population was relatively high (0.244), suggesting the presence of high degree of differentiation between the two watermelon populations. Gene flow among dessert and citron watermelon population was lower $(0.775)$ than one. GD and GI between dessert and citron watermelon population were 2.087 and 0.124 , respectively.

Population difFERENTIATION OF WATERMElon POPUlation BASED ON DISTRICT OF COLLECTION. Genetic parameter estimates of dessert and citron watermelon populations based on district of collection are presented in Table 6 . The mean observed and effective number of detected alleles was higher for landraces collected from Capricorn District, followed by Waterberg and Sekhukhune districts, in that order. Shannon's information index was much higher in Capricorn District, followed by Waterberg and Sekhukhune districts with mean values of 1.8, 1.8 , and 1.5 , respectively. The mean observed and expected heterozygosity were 0.49 and 0.79 for Capricorn District, 0.48 and 0.78 for Waterberg District, and 0.55 and 0.68 for Sekhukhune District, respectively. No significant differences were observed between Capricorn (0.40) and Waterberg (0.39) districts in terms of the mean fixation index; however, Sekhukhune District (0.16) revealed the lowest value, suggesting the environment may favor out crossing in this particular district. PIC and number of private alleles were higher in Capricorn and Waterberg districts compared with Sekhukhune District. Highest polymorphism among dessert and citron watermelon population within the districts of collection was observed and on average, $97 \%$ of the loci were polymorphic (Table 6).

Gene flow among dessert and watermelon population within districts of collection ranged from 2.13 (between Waterberg and Sekhukhune districts) to 17.43 (between Capricorn and Waterberg districts) (Table 7). Genetic differentiation among the districts of collection was lower (0.014) between Waterberg and Capricorn districts but larger $(0.105)$ between Waterberg and Sekhukhune districts. Genetic distance measured by Nei's unbiased genetic distance (Nei, 1978) was higher between accessions collected from Waterberg and Sekhukhune districts and was smaller between Capricorn and Waterberg districts. High genetic distance suggests that watermelon populations collected from these districts are genetically different with low gene flow. Genetic identity, estimate of the proportion of genes that are identical in two populations, was highest between landraces collected from Capricorn and Waterberg districts and smaller between Sekhukhune and Waterberg districts.

Analysis of molecular variance. AMOVA based on dessert and citron watermelon populations are shown in Table 8. Highly significant difference $(P<0.001)$ of molecular variation was observed among populations, among and within individuals.

Table 6. Genetic parameter estimates of dessert watermelon and citron watermelon populations collected from three districts of the Limpopo Province, South Africa.

\begin{tabular}{lcccccccccc}
\hline & \multicolumn{1}{c}{ Genetic parameter $^{2}$} \\
\cline { 2 - 10 } Population/district & $\mathrm{n}$ & $N_{\mathrm{a}}$ & $N_{\mathrm{e}}$ & $I$ & $H_{\mathrm{o}}$ & $H_{\mathrm{e}}$ & $F$ & PIC & PPL & NPA \\
\hline Capricorn & 34 & 10.10 & 5.45 & 1.83 & 0.49 & 0.79 & 0.40 & 0.78 & 100.00 & 20.00 \\
Waterberg & 20 & 8.80 & 5.20 & 1.76 & 0.48 & 0.78 & 0.39 & 0.76 & 100.00 & 17.00 \\
Sekhukhune & 11 & 7.10 & 4.45 & 1.49 & 0.55 & 0.68 & 0.16 & 0.65 & 90.00 & 14.00 \\
Mean & 21.30 & 8.67 & 5.03 & 1.70 & 0.51 & 0.75 & 0.32 & 0.73 & 96.67 & - \\
SE & 1.72 & 0.70 & 0.43 & 0.11 & 0.05 & 0.04 & 0.06 & 0.04 & 3.33 & - \\
\hline
\end{tabular}

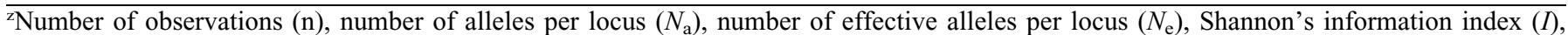
observed $\left(H_{\mathrm{o}}\right)$ and expected $\left(H_{\mathrm{e}}\right)$ heterozygosity, fixation index $(F)$, polymorphic information content (PIC), percentage polymorphic loci (PPL), number of private alleles (NPA). 
Table 7. Pairwise estimates of gene flow (above diagonal, within the brackets), genetic differentiation (above diagonal without brackets); genetic distance (lower diagonal without brackets) and genetic identity (lower diagonal within the brackets) between dessert watermelon and citron watermelon landraces collected from three districts of the Limpopo Province, South Africa.

\begin{tabular}{lccc}
\hline Population/district & Capricorn & Waterberg & Sekhukhune \\
\hline Capricorn & & $0.014(17.43)$ & $0.066(3.54)$ \\
Waterberg & $0.022(0.973)$ & & $0.105(2.13)$ \\
Sekhukhune & $0.206(0.814)$ & $0.497(0.609)$ & \\
\hline
\end{tabular}

Table 8. Analysis of molecular variance based on dessert watermelon and citron watermelon populations collected in South Africa. ${ }^{z}$

\begin{tabular}{lrcrccc}
\hline Source of variation & \multicolumn{1}{c}{ df } & \multicolumn{1}{c}{ SS } & \multicolumn{1}{c}{ MS } & EV & PV & F statistic \\
\hline Among populations & 1 & 105.61 & 105.61 & 1.57 & $33 \%$ & 0.001 \\
Among individuals & 63 & 248.93 & 3.95 & 0.75 & $16 \%$ & 0.001 \\
Within individuals & 65 & 159.5 & 2.45 & 2.45 & $51 \%$ & 0.001 \\
Total & 129 & 514.05 & & 4.77 & $100 \%$ & \\
\hline
\end{tabular}

${ }^{\mathrm{z}}$ Sum of squares (SS), mean squares (MS), estimated variance (EV), percentage variance $(\mathrm{PV})$.

Table 9. Analysis of molecular variance of dessert watermelon and citron watermelon populations based on districts of collection in South Africa. ${ }^{\mathrm{z}}$

\begin{tabular}{lrcrcrc}
\hline Source of variation & \multicolumn{1}{c}{ df } & \multicolumn{1}{c}{ SS } & \multicolumn{1}{c}{ MS } & EV & PV & F statistic \\
\hline Among populations & 2 & 22.31 & 11.16 & 0.15 & $4 \%$ & 0.002 \\
Among individuals & 62 & 332.24 & 5.36 & 1.45 & $36 \%$ & 0.001 \\
Within individuals & 65 & 159.5 & 2.45 & 2.45 & $61 \%$ & 0.001 \\
Total & 129 & 514.05 & & 4.05 & $100 \%$ & \\
\hline
\end{tabular}

${ }^{\mathrm{z}}$ Sum of squares (SS), mean squares (MS), estimated variance (EV), percentage variance $(\mathrm{PV})$.

The largest genetic variability $(51 \%)$ was attributed to variation within individuals, whereas $33 \%$ of the total variation was explained by variation among dessert and citron watermelon populations and $16 \%$ of the variation was among individuals (Table 8). This signifies that one-third of the total genetic variation observed in South Africa watermelon landraces was attributed by the variability existed between the two dessert and citron watermelon populations.

Partitioning of total molecular variance among and within watermelon based on district of collection is presented in Table 9 . There was a highly significant difference $(P<0.001)$ of molecular variance among populations, among and within individuals. The largest genetic variability $(61 \%)$ was attributed to variation within individuals, whereas $36 \%$ of the total variation was explained by variation among individuals and $4 \%$ of variation was explained among population (Table 9). This signifies that the district of collection of dessert and citron watermelon had small but significant contribution to the total molecular variances observed and that the maximum variation was among and within individuals.

Cluster AND PRINCIPAL COORDINATE ANALYSES. Elucidation of relatedness among the watermelon landraces by neighborjoining algorithm using the unweighted pair group method revealed two distinct main clusters (Fig. 5). Cluster I consisted of only dessert watermelon landraces, whereas cluster II consisted of only citron watermelon landraces. Further, principal coordinate analysis was constructed to examine the genetic clustering of dessert and citron watermelon landraces using genetic distances (Fig. 6). The percentages of variance for the first two principal coordinates were $46.4 \%$ and $6.0 \%$ providing a total variance of $52.4 \%$. Based on the principal coordinate analysis, dessert and citron watermelon landraces were classified into two major groups signifying that the two groups are genetically distinct.

\section{Discussion}

The present study assessed genetic diversity of South African dessert and citron watermelon landraces using SSR markers. The SSR markers generated a total of 135 putative alleles (different fragment size) in both sampled populations (Table 3). This was higher than 133 alleles detected by Zhang et al. (2016) who evaluated 23 SSR markers on 1197 watermelon core collections. Nimmakayala et al. (2009) reported a total of 169 alleles amplified in watermelon cultivars. In the current study, the number of alleles per locus ranged from 2 to 23 alleles, with a mean of 13.5 alleles. This was higher than the two and seven alleles (mean $=3.7$ alleles) reported by Zhang et al. (2012). Number of effective alleles ranged from 1.99 to 10.88 alleles with a mean of 5.83 alleles. Observed heterozygosity values in this study ranged from 0.05 to 0.98 with a mean of 0.5 . Mean expected heterozygosity, as a measure of allelic diversity at a locus, was 0.79 . The observed and expected heterozygosity values observed in the current study are higher than the mean value of 0.31 and 0.38 reported by Minsart et al. (2011) among watermelon cultivars. This difference is probably due to higher number of detected alleles per locus (Nyaligwa et al., 2015) due to the outcrossing nature of watermelon. The high mean values for observed heterozygosity and expected heterozygosity in this study suggested high level of heterozygosity among the tested watermelon landrace collections. Further, this indicates a high level of genetic diversity among South African dessert and citron watermelon landraces. The mean fixation index recorded in the present study was 0.39 suggesting that watermelon populations were relatively heterozygous, which is explained by the mode of reproduction of the crop. The PIC for the 10 SSR markers for tested watermelon populations ranged from 0.5 to 0.91 , with a mean of 0.79 . Using SSR loci, Joobeur et al. (2006), Kwon et al. (2010), Mujaju et al. (2011), and Zhang et al. (2016) reported mean PIC values 0.53, $0.50,0.54$, and 0.49 , respectively in dessert and citron watermelon populations which is relatively less than the current findings. High levels of polymorphism observed in the present watermelon populations is ascribed to increased level of genetic divergence or large number of sampled plants per accession (40 plants per entry) than previous studies. In the current study, $80 \%$ of the SSR markers revealed the highest PIC values greater than 0.75 suggesting the potential of these loci for genetic diversity analysis. The SSR markers used in this study have been reported to possess higher discriminatory potential for genetic diversity analysis in watermelon (Joobeur et al., 2006; Kwon et al., 2010; Mujaju et al., 2010; Nantoumé et al., 2013; Zhang et al., 2012, 2016).

The mean expected heterozygosity $(0.53)$ and observed heterozygosity $(0.66)$ values of the dessert watermelon population were higher than those in citron watermelon populations, 0.48 and 0.60 , respectively (Table 4). The expected and observed heterozygosity values found in this study are much comparatively higher than those reported by Mujaju et al. (2011) at 0.12 and 0.12 in dessert watermelon and 0.09 and 0.12 , in citron 


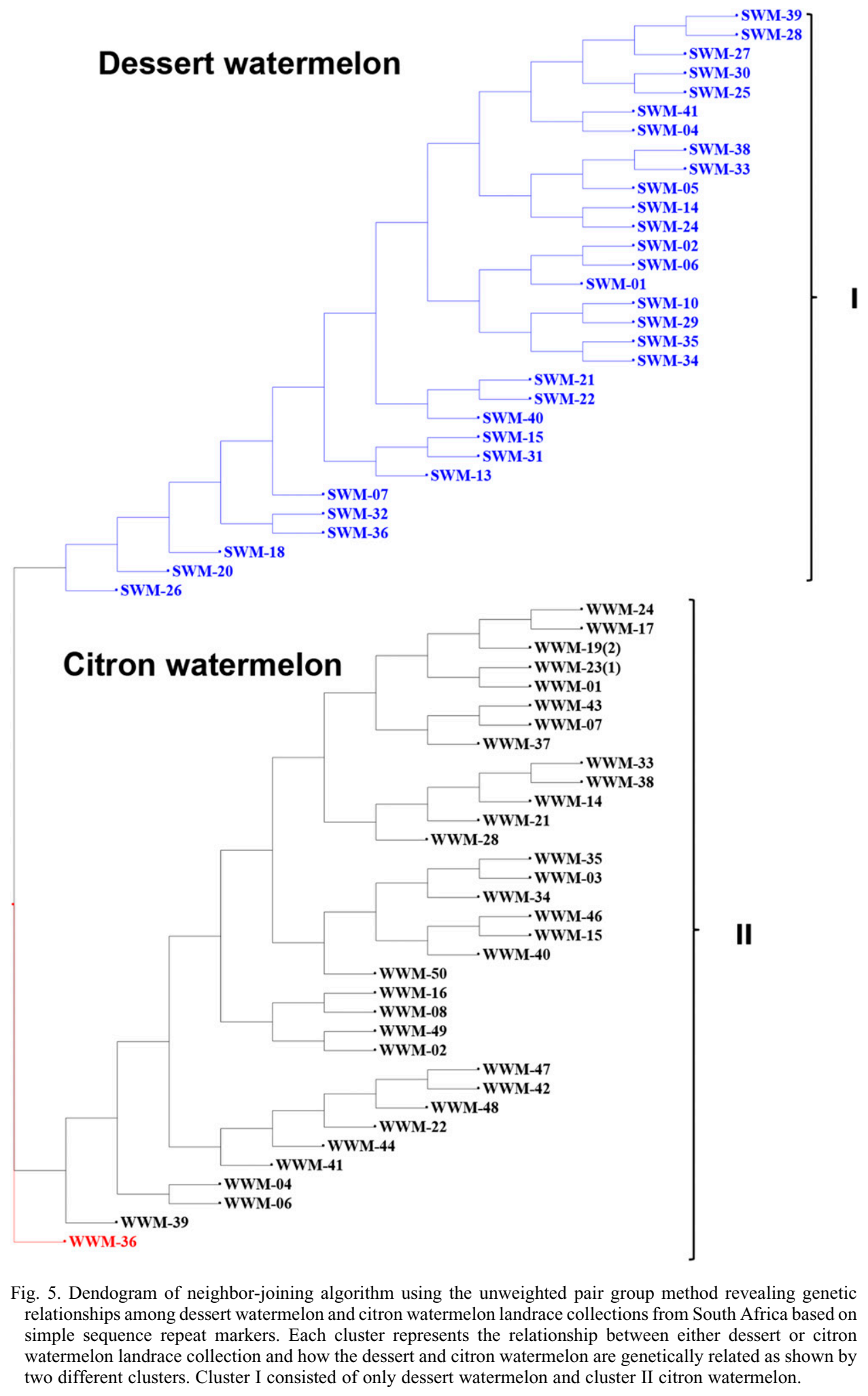

were 1.53 and 1.36 , respectively. These values are higher than the corresponding values estimated at 0.18 and 0.15 in dessert watermelon and citron watermelon populations, in that order reported by Mujaju et al. (2011). Joobeur et al. (2006) and Kwon et al. (2010) reported mean PIC values of 0.53 and 0.50 in dessert and citron watermelon populations, respectively. These values were comparatively lower than the 0.65 and 0.59 recorded in the present study, respectively. There were no differences detected in fixation index and percentage polymorphic loci between the two populations indicating that most of the alleles detected were identical (Levi et al., 2012; Navot and Zamir, 1987; Zhang et al., 2012). In the present study, dessert watermelon population expressed the highest values for most genetic parameters as compared with the citron watermelon population. This suggests the high degree of genetic differentiation between the two populations in agreement to previous findings (Joobeur et al., 2006; Mujaju et al., 2010).

Genetic differentiation and gene flow are important parameters for evaluating the genetic structure of populations. The magnitudes of between and within population differentiation were quantified using the F-statistics according to Wright (1951). A high $F_{\mathrm{ST}}$ of 0.24 was found in the present study between dessert and citron watermelon populations (Table 5). According to Wright (1978), $F_{\mathrm{ST}}$ values ranging from 0 to 0.005 indicates low, $0.05-$ 0.15 moderate, $0.15-0.25$ high, and above 0.25 very high genetic differentiations. The high $F_{\mathrm{ST}}$ value in this study indicates the possibility of considerable genetic differences between dessert and citron watermelon genotypes. High $F_{\mathrm{ST}}$ values could be attributed to the result of low level of gene flow among genotypes. There is little information regarding the magnitude of gene flow

watermelon populations, respectively. Previous studies reported higher levels of genetic diversity within citron watermelon than dessert watermelon (Dane and Liu, 2007; Navot and Zamir, 1987). Conversely, the current study revealed the existence of higher genetic diversity among the tested dessert watermelon landraces. Mean Shannon's information index within dessert watermelon and citron watermelon population among Citrullus species (Achigan-Dako et al., 2015; Zhang et al., 2016). In this study, gene flow between dessert and citron watermelon populations was (0.775) suggesting a low genetic introgression (Table 5). According to Morjan and Rieseberg (2004), $N_{\mathrm{m}}<1$ is considered to be low whereas $N_{\mathrm{m}}=1$ is considered to be moderate. Moderate or relatively low levels of gene flow can significantly reduce loss of genetic diversity 


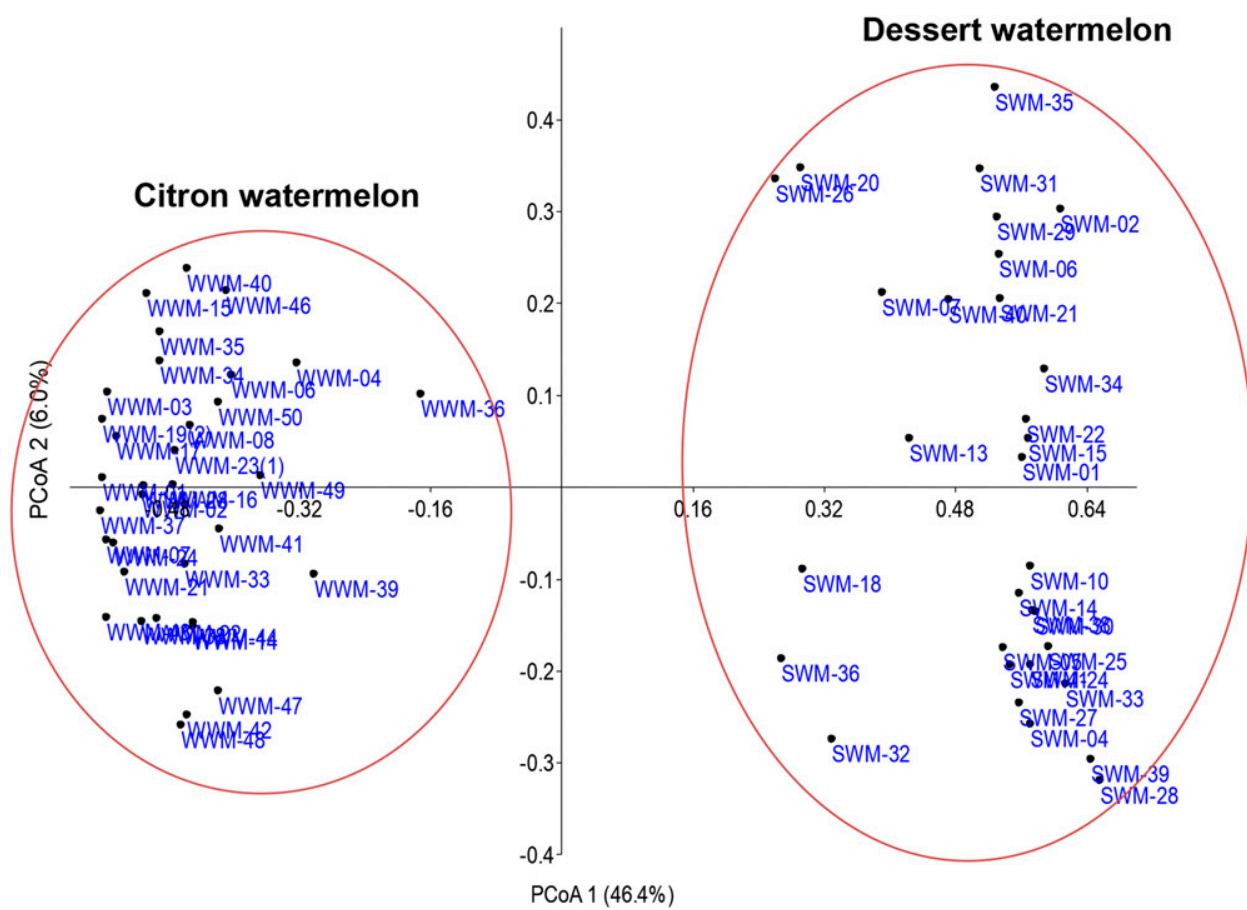

Fig. 6. Principal component coordinates analysis showing two groupings between dessert watermelon and citron watermelon populations from South Africa assessed by simple sequence repeat markers. Each circle represents the relationship between dessert or citron watermelon landraces and the two groups were genetically separated. The percentages of variance for the first two principal coordinates were $46.4 \%$ and $6.0 \%$, providing a total variance of $52.4 \%$

(Aguilar et al., 2008; Djè et al., 1999). Using population structure analysis, Levi et al. (2012) observed the existence of a large number of citron watermelon population that were middle positions between dessert and citron watermelon indicating that gene flow exists among these two botanical varieties. In South Africa, smallholder farmers often grow diverse dessert and citron watermelon landraces in one field and possible outcrossing is highly probable. Such mixed cropping enhances gene flow due to random pollination through bees (Mujaju et al., 2010). In this particular study, both distance- and population-based analysis indicated that the two groups were isolated and no intermediate forms were detected. Although, both of these species are monoecious and naturally outcrossing (Jaskani et al., 2005) with outcrossing rate of about $75 \%$ (Ferreira et al., 2008). Some reports also indicated that dessert watermelon is compatible with citron watermelon (Levi et al., 2001a; Robinson, 2000). Some studies indicated that low fruit set and diminished pollen viability were observed in the intraspecific crosses (Ren et al., 2012; Sandlin et al., 2012). This resulted in successful development of genetic linkage map for watermelon based on crosses between the two botanical varieties (Hashizume et al., 1996, 2003; Levi et al., 2002, 2011b; Ren et al., 2012; Sandlin et al., 2012). Whether outcrossing between the two species will enhance or reduce genetic diversity is yet to be determined.

Genetic differentiation among districts of collection was low (Table 7). For instance, the genetic differentiation between Capricorn and Waterberg districts was 0.014 probably due to the high level of gene flow (17.43). The high level of gene flow observed may be attributed to an exchange of seed materials (Bhawna et al., 2014) between farmers in the two districts leading to low levels of genetic differentiation (Bhawna et al., 2015). This was supported by a low value of genetic distance (0.002) and high genetic identity (0.973). Similarly, moderate levels of genetic differentiation and high levels of gene flow $(>2)$ were observed between the Capricorn and Sekhukhune districts at 0.066 and 3.54 and Waterberg and Sekhukhune districts with 0.105 and 2.13 , respectively. This may suggest low exchange of germplasm between the districts, which may lead to high genetic differentiation explained by high values of genetic distances and low genetic identity between districts (Table 7). The high genetic distances and slightly low genetic identity between the districts of collection could be attributed to the genetic uniqueness of the material studied. Information regarding the prevailing farming systems and genetic management in the districts of collection may further explain differences in genetic variability (Minsart et al., 2011).

AMOVA based on dessert and citron watermelon population revealed that $33 \%, 16 \%$, and $51 \%$ of the variation was due to among populations, among individuals, and within individuals' variation, respectively (Table 8). Further, AMOVA based on district of collection revealed presence of $61 \%, 36 \%$, and $4 \%$ of variation attributed to among populations, within and among individuals, respectively (Table 9). Results of the present study agree with Mujaju et al. (2011) and Minsart et al. (2011) who reported similar trends of variation among and between watermelon cultivars. Munisse et al. (2013) and Nantoumé et al. (2013) showed that $63 \%$ and $37 \%$ and $51 \%$ and $49 \%$ of total variation was among and within seed and dessert watermelon cultivars, respectively.

Cluster and principal coordinate analyses classified the sampled dessert and citron watermelon landraces into two major clusters revealing high genetic differentiation (Figs. 5 and 6). Previous studies using SSR markers unambiguously differentiated dessert and citron watermelon cultivars (Kwon et al., 2010; Levi et al., 2001b; Nantoumé et al., 2013; Sheng et al., 2012; Zhang et al., 2016). Using RAPD markers, HFO and AFLP, Mujaju et al. (2010), Levi et al. (2012), and Che et al. (2003) concluded the existence of distinct grouping among dessert and citron watermelon cultivars. Using peroxidase gene markers (POGP), Ocal et al. (2014) reported independent clustering of dessert and citron watermelon cultivars. Genetic mapping using populations derived from crosses between dessert and citron watermelon cultivars showed strong preferential segregation for a large number of markers (Levi et al., 2001a, 2011a). Levi et al. (2012) observed major differences in ribosomal DNA gene configuration, suggesting substantial differences between dessert and citron watermelon genome structure. Reddy et al. (2013) reported the presence of wide chromosomal structural differences 
between dessert and citron watermelon accessions. Results in the present study agree with previous findings that citron watermelon is genetically different from dessert watermelon. Chomicki and Renner (2014) reported that citron and dessert watermelons are two distinct watermelon species.

The chloroplast and mitochondrial genomes of dessert and citron watermelon cultivars were reported to be different (Levi and Thomas, 2005). In this study, genetic distance and identity between dessert and citron watermelon entries based on Nei (1978) indicated that the Nei's unbiased GD was higher (2.087) and GI was lower $(0.124)$, supporting previous findings that the two botanical varieties are genetically unique (Chomicki and Renner, 2014; Levi et al., 2012).

\section{Conclusions}

Overall, the study established the existence of considerable genetic diversity and useful genetic resources among South African grown dessert and citron watermelon landraces. The following unique dessert watermelon landraces: SWM-39, SWM-24, SWM-01, SWM-40, SWM-18, SWM-36, and SWM-26 and citron watermelon landraces including WWM24, WWM-37, WWM-28, WWM-34, WWM-02, WWM-22, WWM-50, and WWM-36 were selected based on their highest dissimilarity index. These are valuable genetic resources for watermelon breeding and systematic conservation. Seed stocks of the studied germplasm collections are available on request.

\section{Literature Cited}

Achigan-Dako, E.G., E.S. Avohou, C. Linsoussi, A. Ahanchede, R.S. Vodouhe, and F.R. Blattner. 2015. Phenetic characterization of Citrullus spp. (Cucurbitaceae) and differentiation of egusi-type (C. mucosospermus). Genet. Resources Crop Evol. 62:1159-1179.

Aguilar, R., M. Quesada, L. Ashworth, Y. Herrerias-Diego, and J. Lobo. 2008. Genetic consequences of habitat fragmentation in plant populations: Susceptible signals in plant traits and methodological approaches. Mol. Ecol. 17:5177-5188.

Bhawna, A.M.Z., L. Arya, D. Saha, A.K. Sureja, C. Pandey, and M. Verma. 2014. Population structure and genetic diversity in bottle gourd [Lagenaria siceraria (Mol.) Standl.] germplasm from India assessed by ISSR markers. Plant Syst. Evol. 300:767-773.

Bhawna, A.M.Z., L. Arya, C. Ram, A.K. Sureja, and M. Verma. 2015. Development of novel gene-based microsatellite markers for robust genotyping purposes in Lagenaria siceraria. Sci. Hort. 191:15-24.

Che, K.P., C.Y. Liang, Y.G. Wang, D.M. Jin, and B. Wang. 2003. Genetic assessment of watermelon germplasm using the AFLP technique. HortScience 38:81-84.

Chomicki, G. and S.S. Renner. 2014. Watermelon origin solved with molecular phylogenetics including Linnaean material: Another example of museomics. New Phytol. 205:526-532.

CIMMYT. 2005. Laboratory protocols: CIMMYT: Applied molecular genetics laboratory 3rd ed. CIMMYT, DF, Mexico.

Dane, F. and P. Lang. 2004. Sequence variation at cpDNA regions of watermelons and related citron species: Implications for evolution of Citrullus haplotypes. Amer. J. Bot. 91:1922-1929.

Dane, F. and J. Liu. 2007. Diversity and origin of cultivated and citron type watermelon (Citrullus lanatus). Genet. Resources Crop Evol. 54:1255-1265.

Davis, A.R., A. Levi, A. Tetteh, T. Wehner, V. Russo, and M. Pitrat. 2007. Evaluation of watermelon and related species for resistance to race $1 \mathrm{~W}$ powdery mildew. J. Amer. Soc. Hort. Sci. 132:790-795.

Djè, Y., D. Forcioli, M. Ater, C. Lefèbvre, and X. Vekemans. 1999. Assessing population genetic structure of sorghum landraces from north-western Morocco using allozyme and microsatellite markers. Theor. Appl. Genet. 99:157-163.
Ferreira, M.A.J., D. Vencovsky, R. Vieira, and M.L.C. de Queiro. 2008. Outcrossing rate and implications for the improvement of a segregating population of watermelon. Acta Hort. 510):47-54.

Gong, L., H.S. Paris, M.H. Nee, G. Stift, M. Pachner, J. Vollmann, and T. Lelley. 2012. Genetic relationships and evolution in Cucurbita pepo (pumpkin, squash, gourd) as revealed by simple sequence repeat polymorphisms. Theor. Appl. Genet. 124:875-891.

Gusmini, G., G. Song, and T.C. Wehner. 2005. New sources of resistance to gummy stem blight in watermelon. Crop Sci. 45:582-588.

Hammer, Ø., D.A.T. Harper, and R.D. Ryan. 2001. PAST: Paleontological statistics software package for education and data analysis. Palaeontol. Electronica 4:1-9.

Hashizume, T., I. Shimamoto, Y.M. Harusima, T. Sato, T. Imai, and M. Hirai. 1996. Construction of a linkage map for watermelon (Citrullus lanatus) using random amplified polymorphic DNA (RAPD). Euphytica 90:265-273.

Hashizume, T., I. Shimamoto, and M. Hirai. 2003. Construction of a linkage map and QTL analysis of horticultural traits for watermelon [Citrullus lanatus (Thumb.) Matsum \& Nakai] using RAPD, RFLP and ISSR markers. Theor. Appl. Genet. 106:779-785.

Hwang, J.H., S.G. Ahn, J.Y. Oh, Y.W. Choi, J.S. Kang, and Y.H. Park. 2011. Functional characterization of watermelon (Citrullus lanatus L.) EST-SSR by gel electrophoresis and high resolution melting analysis. Sci. Hort. 130:715-724.

Jarret, R.L., L.C. Merrick, T. Holms, J. Evans, and M.K. Aradhya. 1997. Simple sequence repeats in watermelon (Citrullus lanatus (Thunb.) Matsum. \& Nakai). Genome 40:433-441.

Jaskani, M.J., S.W. Kwong, and D.H. Kim. 2005. Comparative study on vegetative, reproductive and qualitative traits of seven diploid and tetraploid watermelon lines. Euphytica 145:259-265.

Ji, Y., Y. Luo, B. Hou, W. Wang, J. Zhao, L. Yang, Q. Xue, and X. Ding. 2012. Development of polymorphic microsatellite loci in Momordica charantia (Cucurbitaceae) and their transferability to other cucurbit species. Sci. Hort. 140:115-118.

Joobeur, T., G. Gusmini, X. Zhang, A. Levi, Y. Xu, T.C. Wehner, M. Oliver, and R.A. Dean. 2006. Construction of a watermelon BAC library and identification of SSRs anchored to watermelon or Arabidopsis genomes. Theor. Appl. Genet. 112:1553-1562.

Kwon, Y.S., Y.H. Oh, S.I. Yi, H.Y. Kim, J.M. An, S.Y. Yang, S.H. Ok, and J.S. Shin. 2010. Informative SSR markers for commercial variety discrimination in watermelon (Citrullus lanatus). Genes Genome 32:115-122.

Levi, A., C.E. Thomas, A.P. Keinath, and T.C. Wehner. 2001a. Genetic diversity among watermelon (Citrullus lanatus and Citrullus colocynthis) accessions. Genet. Resources Crop Evol. 48:559-566.

Levi, A., C.E. Thomas, T.C. Wehner, and X. Zhang. 2001b. Low genetic diversity indicates the need to broaden the genetic base of cultivated watermelon. HortScience 36:1096-1101.

Levi, A., E. Thomas, T. Joobeur, X. Zhang, and A. Davis. 2002. A genetic linkage map for watermelon derived from a testcross population: (Citrullus lanatus var. citroides $\times$ C. lanatus var. lanatus) x Citrullus colocynthis. Theor. Appl. Genet. 105:555-563.

Levi, A. and C.E. Thomas. 2005. Polymorphisms among chloroplast and mitochondrial genomes of Citrullus species and subspecies. Genet. Resources Crop Evol. 52:609-617.

Levi, A., W.P. Wechter, L.M. Massey, L. Carter, and D. Hopkins. 2011a. Genetic linkage map of Citrullus lanatus var. citroides chromosomal segments introgressed into the watermelon cultivar Crimson Dessert (Citrullus lanatus var. lanatus) genome. Amer. J. Plant Sci. 2:93-110.

Levi, A., W.P. Wechter, L.M. Massey, L. Carter, and D. Hopkins. 2011b. An extended genetic linkage map for watermelon based on a testcross and $\mathrm{BC}_{2} \mathrm{~F}_{2}$ population. Amer. J. Plant Sci. 2:93-110.

Levi, A., J.A. Thies, W.P. Wechter, H.F.J. Harrison, A.M. Simmons, U. Reddy, P. Nimmakayala, and Z. Fei. 2012. High frequency oligonucleotides-Targeting active gene (HFO-TAG) markers reveal wide genetic diversity among Citrullus spp. accessions useful 
for enhancing disease or pest resistance in watermelon cultivars. Genet. Resources Crop Evol. 60:427-440.

Ma, S. and T.C. Wehner. 2015. Flowering stage resistance to bacterial blotch in the watermelon germplasm collection. Crop Sci. 55:727-736. McGregor, C. 2012. Citrullus lanatus germplasm of southern Africa. Isr. J. Plant Sci. 60:403-413.

Minsart, L.A., I.A. Zoro Bi, Y. Dje', J.P. Baudoin, A.L. Jacquemart, and P. Bertin. 2011. Set up of simple sequence repeat markers and first investigation of the genetic diversity of west-African watermelon (Citrullus lanatus ssp. vulgaris oleaginous type). Genet. Resources Crop Evol. 58:805-814.

Morjan, C.L. and L.H. Rieseberg. 2004. How species evolve collectively: Implications of gene flow and selection for the spread of advantageous alleles. Mol. Ecol. 13:1341-1356.

Mujaju, C., J. Sehic, G. Werlemark, L. Garkava-Gustavsson, M. Fatih, and H. Nybom. 2010. Genetic diversity in watermelon (Citrullus lanatus) landraces from Zimbabwe revealed by RAPD and SSR markers. Hereditas 147:142-153.

Mujaju, C., A. Zborowska, G. Werlemark, L. Garkava-Gustavssson, S.B. Andersen, and H. Nybom. 2011. Genetic diversity among and within watermelon (Citrullus lanatus) landraces in southern Africa. J. Hort. Sci. Biotechnol. 86:353-358.

Munisse, P., B.D. Jensen, and S.B. Andersen. 2013. Genetic differentiation of watermelon landraces in Mozambique using microsatellite markers. Afr. J. Biotechnol. 12:5513-5521.

Nagy, S., P. Poczai, I. Cernák, A.M. Gorji, G. Hegedüs, and J. Taller. 2012. PIC calc: An online program to calculate polymorphic information content for molecular genetic studies. Biochem. Genet. 50:670-672.

Nantoumé, A.D., S.B. Andersen, and B.D. Jensen. 2013. Genetic differentiation of watermelon landrace types in Mali revealed by microsatellite (SSR) markers. Genet. Resources Crop Evol. 60:2129-2141.

Navot, N. and D. Zamir. 1987. Isozyme and seed protein phylogeny of the genus Citrullus (Cucurbitaceae). Plant Syst. Evol. 56:61-67.

Nei, M. 1978. Estimation of average heterozygosity and genetic distance from a small number of individuals. Genet. Mol. Rpt. 89:583-590.

Nei, M. and W. Li. 1979. Mathematical method for studying genetic variation in terms of restriction endonucleases. Proc. Natl. Acad. Sci. USA 76:5256-5273.

Nimmakayala, P., Y.R. Tomason, J. Jeong, S.K. Ponniah, A. Karunathilake, A. Levi, R. Perumal, and U.K. Reddy. 2009. Genetic reticulation and interrelationships among Citrullus species as revealed by joint analysis of shared AFLPs and species-specific SSR alleles. Plant Genet. Resour. 8:16-25.

Nyaligwa, L., H. Shimelis, A. Beyene, and G. Habteab. 2015. Genetic diversity analysis of elite maize inbred lines of diverse sources using SSR markers. Maydica 60:1-8.

Ocal, N., M. Akbulut, G.O. Osman, H. Yetisir, I. Solmaz, and N. Sari. 2014. Genetic diversity, population structure and linkage disequilibrium among watermelons based on peroxidase gene markers. Sci. Hort. 176:151-161.

Peakall, R. and P.E. Smouse. 2012. GenAlEx 6.5: Genetic analysis in Excel. Population genetic software for teaching and research:An update. Bioinformatics 28:2537-2539.

Perrier, X. and J.P. Jacquemoud-Collet. 2006. DARwin software. Dissimilarity analysis and representation for Windows. 20 Apr. 2016. <http://www.darwin.cirad.fr/darwinhtml>.

Reddy, U., N. Aryal, N. Islam-Faridi, Y. Tomason, A. Levi, and P. Nimmakayala. 2013. Cytomolecular characterization of rDNA distribution in various Citrullus species using fluorescent in situ hybridization. Genet. Resources Crop Evol. 60:2091-2100.
Ren, Y., H. Zhao, Q. Kou, J. Jiang, and S. Guo. 2012. A high resolution genetic map anchoring scaffolds of the sequenced watermelon genome. PLoS One 7:e29453.

Robinson, R.W. 2000. Rationale and methods for producing hybrid cucurbit seed. J. New Seeds 1:1-47.

Robinson, R.W. and D.S. Decker-Walters. 1997. Cucurbits. CABI Publ., Cambridge, UK.

Rubatzky, V.E. 2001. Origin, distribution and uses, p. 21-26. In: D.N. Maynard (ed.). Watermelons: Characteristics, production and marketing, ASHS Press, Alexandria, VA.

Sandlin, K., J. Prothro, A. Heesacker, N. Khalilian, R. Okashah, W. Xiang, E. Bachlava, D.G. Caldwell, C.A. Taylor, D.K. Seymour, V. White, E. Chan, G. Tolla, C. White, D. Safran, E. Graham, S. Knapp, and C. Mcgregor. 2012. Comparative mapping in watermelon (Citrullus lanatus (Thunb.) Matsum. et Nakai). Theor. Appl. Genet. 125:1603-1618.

Sheng, Y., F. Luan, F. Zhang, and R.A. Davis. 2012. Genetic diversity within Chinese watermelon ecotypes compared with germplasm from other countries. J. Amer. Soc. Hort. Sci. 137:144-151.

Solmaz, I. and N. Sari. 2009. Characterization of watermelon (Citrullus lanatus) accessions collected from Turkey for morphological traits. Genet. Resources Crop Evol. 56:173-188.

Solmaz, I., N. Sari, Y. Aka-Kacar, and N.Y. Yalcin-Mendi. 2010. The genetic characterization of Turkish watermelon (Citrullus lanatus) accessions using RAPD markers. Genet. Resources Crop Evol. 57:763-771.

Tetteh, A.Y., T.C. Wehner, and A.R. Davis. 2010. Identifying resistance to powdery mildew race $2 \mathrm{~W}$ in the USDA-ARS watermelon germplasm collection. Crop Sci. 50:933-939.

Thies, J.A., J.J. Ariss, R.L. Hassell, S. Olson, C.S. Kousik, and A. Levi. 2010. Grafting for management of southern root-knot nematode, Meloidogyne incognita, in watermelon. Plant Dis. 94:1195-1199.

Thies, J.A., A. Levi, J.J. Ariss, and R.L. Hassell. 2015. RKVL-318, a root-knot nematode-resistant watermelon line as rootstock for grafted watermelon. HortScience 50:141-142.

Uluturk, Z.I., A. Frary, and S. Doganlar. 2011. Determination of genetic diversity in watermelon [Citrullus lanatus (Thunb.) Matsum \& Nakai] germplasm. Austral. J. Crop Sci. 5:1832-1836.

Varshney, R.K., A. Graner, and M.E. Sorrells. 2005. Genic microsatellite markers in plants: Features and applications. Trends Biotechnol. 23:48-55.

Weng, Y., A. Davis, and Y. Xu. 2016. Genetic diversity, population structure, and formation of a core collection of 1197 Citrullus accessions. HortScience 51:23-29.

Whitaker, T.W. and G.N. Davis. 1962. Cucurbits: Botany, cultivation and utilization Interscience Publ., New York, NY.

Wright, S. 1951. The genetical structure of populations. Ann. Eugen. $15: 323-354$

Wright, S. 1978. Evolution and the genetics of populations: Variability within and among natural populations Univ. Chicago Press, Chicago, IL.

Yang, X., R. Ren, R. Ray, J. Xu, P. Li, M. Zhang, G. Liu, X. Yao, and A. Kilian. 2016. Genetic diversity and population structure of core watermelon (Citrullus lanatus) genotypes using DArTseq-based SNPs. Plant Genet. Resour. 1:1-8.

Zhang, H., J. Fan, S. Guo, Y. Ren, G. Gong, and J. Zhang. 2016. Genetic diversity, population structure, and formation of a core collection of 1197 Citrullus accessions. HortScience 51:23-29.

Zhang, H., H. Wang, S. Guo, Y. Ren, G. Gong, Y. Weng, and Y. Xu. 2012. Identification and validation of a core set of microsatellite markers for genetic diversity analysis in watermelon, Citrullus lanatus Thunb. Matsum. \& Nakai. Euphytica 186:329-342. 